OPEN ACCESS

Edited by:

Karlein M. G. Schreurs, University of Twente, Netherlands

Reviewed by:

Hester Trompetter, University of Twente, Netherlands Olöf Birna Kristjansdottir, Oslo University Hospital, Norway

${ }^{*}$ Correspondence: Geert Crombez geert.crombez@ugent.be

Specialty section: This article was submitted to Psychology for Clinical Settings, a section of the journal

Frontiers in Psychology

Received: 20 March 2016 Accepted: 10 June 2016

Published: 28 June 2016

Citation:

Crombez G, Lauwerier E, Goubert L and Van Damme S (2016) Goal Pursuit in Individuals with Chronic Pain: A Personal Project Analysis. Front. Psychol. 7:966. doi: 10.3389/fpsyg.2016.00966

\section{Goal Pursuit in Individuals with Chronic Pain: A Personal Project Analysis}

\author{
Geert Crombez ${ }^{1,2 *}$, Emelien Lauwerier ${ }^{3}$, Liesbet Goubert ${ }^{1}$ and Stefaan Van Damme ${ }^{1}$ \\ ${ }^{1}$ Department of Experimental-Clinical and Health Psychology, Ghent University, Gent, Belgium, ${ }^{2}$ Center for Pain Research, \\ University of Bath, Bath, UK, ${ }^{3}$ Department of Health and Well-being, University Colleges Leuven-Limburg, Leuven, Belgium
}

Objectives: In individuals with chronic pain (ICPs), controlling pain often is a salient goal, despite the difficulty to achieve it. This situation may bring along frustration and distress. Yet much remains unknown about the content, appraisal, and structure of goals that ICPs pursue. Here, we explore these goals, and specifically focus upon possible differences and interrelations between pain control goals (e.g., "to control my pain") and non-pain goals (e.g., "to go to work").

Design and Methods: "Personal Project Analysis" was used in 73 ICPs (48 females; 25 males; $M_{\text {age }}=49.85$ years; $S D=9.72$ ) to elicit goals and goal appraisals. Interrelations between pain and non-pain goals, namely interference (i.e., negative influence), facilitation (i.e., positive influence), and necessary condition (i.e., conditional relation between pain control goal and non-pain goals) were measured with three items. Self-report measures of pain intensity, pain catastrophizing, problem solving and acceptance were completed.

Results: Participants reported a variety of goals. Appraisals of pain control goals were less favorable than appraisals of non-pain goals. ICPs with higher acceptance and meaningfulness of life reported more control over pain goals, and more progress in reaching pain control goals. These individuals also reported an overall much more positive appraisal of non-pain goals (i.e., less stress, difficulty, more progress, control). In contrast, high catastrophizing and the need to solve pain were negatively related to goal appraisals. Importantly, ICP's with high perceived meaningfulness of life despite pain experienced less necessity to achieve pain control goals in order to achieve non-pain goals. This was opposite for individuals with high levels of catastrophizing.

Discussion: An understanding of why ICPs may become stuck in attempts to control their pain does not only require an understanding of how individuals appraise their pain, but also requires an understanding of how pain and non-pain goals interrelate. In particular, the view that controlling pain is necessary in order to be able to achieve other goals seems detrimental.

Keywords: chronic pain, goals, catastrophizing, problem solving, acceptance 


\section{INTRODUCTION}

Some individuals with chronic pain (ICPs) adjust well to their pain. Others report high levels of interference of their daily activities by pain, and experience distress and despair (McCracken and Eccleston, 2003, 2005; Viane et al., 2003). Research has attempted to understand why these individuals are stuck in a vicious circle of enduring pain, disability and suffering. It has been proposed that distress and suffering result from a rigid search for a solution with regard to an experience that (unfortunately) cannot be controlled (McCracken and Eccleston, 2003; Eccleston and Crombez, 2007). Indeed, medical treatments often cannot provide satisfying pain relief for ICPs. Nevertheless, ICPs may remain searching for a solution, and this search may start to dominate their life at the expense of the pursuit of other valued activities.

Trying to solve the problem of chronic pain, or at least reducing it to an acceptable level, is typically the first response to pain-induced goal disturbance (Eccleston and Crombez, 2007; Van Damme et al., 2008). ICPs may then engage in a variety of behaviors, such as looking up information on the internet, visiting healthcare providers, taking medication, resting in bed, or avoiding pain-inducing activities. A second possible response is accepting the problem of chronic pain as insoluble. ICPs may then disengage from trying to solve the problem of chronic pain, and reengage in other valued goals despite the presence of pain (McCracken and Eccleston, 2003). In line with this view, acceptance has been related to favorable outcomes in the context of chronic pain (McCracken and Eccleston, 2003, 2005; Viane et al., 2003). Problems may arise when ICPs persist in futile attempts to solve or control pain at the expense of the pursuit of other valuable life goals. Such attempts have been dubbed 'misdirected problem solving' (Aldrich et al., 2000; Eccleston and Crombez, 2007). In line with this view, attempting to solve the problem of chronic pain has been linked to unfavorable outcomes (De Vlieger et al., 2006; Crombez et al., 2008). Adhering to an agenda of pain control is also believed to more readily occur in those who catastrophize about their pain (De Vlieger et al., 2006), i.e., excessively worry about pain and its possible consequences.

As yet, we do not have a broad understanding of why ICPs may become stuck in attempts to control pain. We also do not have a broad view on how ICPs experience the pursuit of pain control amidst the other goals that often are simultaneously pursued (Crombez et al., 2012). Overall, the assessment of goals in the context of chronic pain is not a wellstudied area. Most of these studies focus on the assessment of non-pain goals in chronic pain (Karoly and Ruehlman, 1996; Karoly and Lecci, 1997; Affleck et al., 1998, 2001; Karoly et al., 2008; Hardy et al., 2011), but do not assess how ICPs construct and appraise their pain control goals. Therefore, this study focuses upon pain goals, in particular the goal to control pain, and their interrelations with other, non-pain, goals.

The present study adopts the "Personal Project Analysis" (PPA, Little, 1983) to assess personal goals and their characteristics. According to PPA, personal projects are "extended sets of personally salient action" (Little and Gee, 2007, p. 25). Typically, a PPA requires respondents to list goals that are currently important to them, to rate these goals on a number of dimensions or appraisals, and to report on the interrelationships between the goals (goal structure). For goal structure, we were particularly interested how working on a pain control goal facilitates the pursuit of other goals (goal facilitation: e.g., "to control pain" allows me "to go to work"), or interferes with the progress on other goals (goal interference: e.g., "to control pain" hinders me "to go out with friends") (Riediger and Freund, 2004). Although the characterization of goal interrelations in terms of facilitation and interference is theoretically well established (Riediger and Freund, 2004), we found that one particular characteristic was lacking. Clinical practice learns that patients often frame their attempts to control pain as a necessary condition to be able to continue with their life (Malec et al., 1977). We believed that this characterization was insufficiently captured under the constructs of goal facilitation and interference (Riediger and Freund, 2004). For that reason, we asked ICPs directly about this feature, which we dubbed "necessary condition" (e.g., "to be able to control pain" is necessary in order "to spend time with family").

Given the current state of research, we opted for an exploratory approach (Rozin, 2009), in which the content, appraisals and structure of the goals that ICPs pursue, were broadly assessed. We sought answers to 4 questions: (1) What types of goals are spontaneously elicited by ICPs?; (2) How do ICPs appraise their pain control goals, and how does this compare with non-pain goal appraisals?; (3) How do pain control goals relate to other, non-pain goals?; (4) Finally, we were interested in whether the goal appraisals and interrelationships were related to some key constructs involved in misdirected problem solving, such as catastrophic thinking about pain, attempts to solve pain and acceptance.

\section{MATERIALS AND METHODS}

\section{Participants}

The present study was part of the GPD-I study consisting of three studies on chronic pain and functioning. More information and details about this study can be found on http://hdl.handle .net/1854/LU-3050986. Participants were recruited from Flemish patient associations from December 2010 onward over a 4-month period. Inclusion criteria were (a) being aged between 18 and 65 years, (b) having sufficient Dutch language skills to fill out self-report measures, and (c) having pain for at least 6 months. Exclusion criteria were (a) reporting headache as a primary complaint, (b) reporting a psychiatric disorder (other than pain disorder) as primary complaint, and (c) physical limitations that made it impossible to participate in computer tasks. Three hundred and fifteen ICPs agreed that they could be contacted for the GPD-I study. Of these 315, 267 ICPs were contacted by phone and invited to participate. Eighty-one ICPs were eligible and agreed to participate in the study. However, 7 ICPs refrained from participation owing to health problems, and one participant was excluded because he/she did not report pain at the moment of testing. 
The final sample consisted of 73 participants (48 females; 25 males; mean age $=49.85$ years; $S D=9.72$ ). Most ICPs were married or living together (69.9\%), 39.4\% had a higher education (longer than the age of 18 years). Only $18.1 \%$ was in paid employment or followed education, $7 \%$ was in unpaid employment, $13.9 \%$ was retired, and $4.2 \%$ was unemployed. All others received disablement insurance benefits $(55.5 \%)$ or were legally trying to receive one (1.4\%). The mean pain duration was 14.04 years $(S D=9.37)$. Back pain was the most reported pain location (90.4\%). Participants also frequently reported pain in other body sites, such as the legs $(67.1 \%)$, neck (67.1\%), arms (46.6\%), and head (32.9\%). On average, participants reported pain on at least three different locations $(M=3.84, S D=1.88)$. Socio-demographic information on non-participants was not available. The Local Ethics Committee of the University approved the study protocol.

\section{Measures \\ Personal Project Analysis}

We followed the guidelines of the Personal Project Analysis (Little, 1983) and conducted a semi-structured interview in which clarification, prompts and feedback were provided to elicit goals. Participants were asked to list all their current goals. We asked participants to report as many personal goals as possible that they had for the near future, currently judged to be important, and still expected to be important in the upcoming months. Whenever ICPs did not spontaneously mention a pain control goal during the free-elicitation phase, we required participants to identify one. We asked participants to write down their goals with a few words or short sentences (Ogilvie et al., 2001).

Goals were coded into 12 categories. We followed a standard coding procedure. Two independent raters were asked for the initial coding. Whenever there was disagreement, a third rater was assigned and recoded until consensus was achieved. The coding was based on existing taxonomies of goals (Chulef et al., 2001) and consisted of the following categories: interpersonal goals (e.g., to keep in touch with friends), intrapersonal goals (e.g., to be loving), health/physical domain goals (e.g., to lose weight), work/education goals (e.g., to do voluntary work), financial goals (e.g., to be financially independent), leisure/entertainment-related goals (e.g., to travel more), and psychological/mental well-being goals (e.g., to be full of energy). When we examined the list of goals participants provided, we decided to add three other categories: one related to householding (e.g., cleaning the house), one related to exercise (e.g., to walk on a daily basis), and one related to social validation of one's pain (Hamilton et al., 2005) (e.g., to be believed that the pain is real). Individuals' pain goal, i.e., the goal to control pain was classified separately as pain control (e.g., to have less pain). Finally, there was a rest category, consisting of all goals that could not be classified into one of the 11 categories above. The inter-rater reliability was high (Cohen's Kappa $=0.77, p<0.001$ ) and there was an overall simple agreement coefficient of $79.5 \%$ (421-86/421).

In line with PPA guidelines (Little, 1983), participants were asked to select their two most important non-pain goals, and their pain control goal. Then, they were asked to rate these goals on a number of appraisal dimensions. A standard set of goal appraisals has been identified (Little, 1989, 1998; Austin and Vancouver, 1996). These usually include the following: meaning (e.g., importance, value congruency, self-identity), structure (e.g., control, time), efficacy (e.g., satisfaction with progress), or stress (e.g., stress, difficulty) (Little and Chambers, 2004). We selected a limited number of dimensions, mainly to avoid mental overload in participants. The following dimensions were included: (1) importance ("This goal is important to me"); (2) difficulty ("I find it hard to achieve this goal"); (3) control ("I feel I am in control of this goal"); (4) stressfulness ("I find it stressful to pursue this goal"); (5) time ("I spend a lot of time in pursuing this goal"); (6) progress ("I am satisfied with the progression I made in achieving this goal"); (7) self-identity ("This goal says a lot about who I am"); and (8) value ("This goal is highly valuable to me"). Each appraisal had to be rated on a 7 -point Likert scale, ranging from 0 , not at all, to 6 , completely.

Goal interrelationships were measured by three items. Items were formulated during an iterative process, and piloted for comprehensibility with ICPs. Participants were instructed to rate the interrelationships of each possible pair of goals from their selected set of three goals, i.e., their pain control goal [C]) and their two most important non-pain goals [A and $B$ ], There were six possible pairs (A-B, B-A, A-C, C-A, B-C, C-B). For each pair of goals, participants rated three items, one item reflecting intergoal interference (e.g., "To what extent does the pursuit of goal $\mathrm{C}$ have a negative influence on the pursuit of goal B?"), one item reflecting intergoal facilitation (e.g., "To what extent does goal $\mathrm{C}$ have a positive influence on the pursuit of goal B?"), and one item reflecting goal necessity (e.g., "To what extent is it necessary to achieve goal $\mathrm{C}$ in order to be able to achieve goal B?"). As such, participants responded to a total of 18 items. All items were rated on a 5 -point Likert scale, ranging from 1 , not at all, to 5, very much. Of importance for this study were the goal interrelationships between the pain control goal and the non-pain goals.

\section{Questionnaires}

Pain severity was measured by means of the two-item pain severity subscale of the Dutch version of the Multidimensional Pain Inventory (MPI; Lousberg et al., 1999) (i.e., "Rate the level of your pain at the present moment", and "On average, how severe has your pain been during the last week"). Ratings are made on a 7-point scale (from 0 to 6). The sum score of the two items may range between 0 and 12. The MPI has been shown to have good reliability and validity. Test-retest reliability $(r=0.71)$ and Cronbach's alpha $(\alpha=0.74)$ of the pain severity subscale are both adequate. Data on construct validity are also adequate (Lousberg et al., 1999). Cronbach's alpha in this study was $\alpha=0.80$.

We used the Pain Solutions Questionnaire (PaSol; De Vlieger et al., 2006) to assess efforts at changing, solving or accepting pain and the problems associated with pain. The PaSol has 14 items grouped into four interrelated scales: (1) solving pain (four items; e.g., "I try everything to get rid of my pain"); (2) meaningfulness of life despite pain (five items; e.g. "Even when I have severe pain, I still find my life meaningful"); (3) acceptance of the insolubility 
of pain (three items; e.g., "I can live with the idea that there is no solution for my pain"); and (4) belief in a solution (two items; e.g., "I am convinced that there is a treatment for my pain"). Participants are instructed to describe the degree to which each statement applies to them. Each item is answered on a 7point Likert scale, ranging from 0 , not at all applicable, to 6, highly applicable. Although the original PaSol has demonstrated good reliability and validity (De Vlieger et al., 2006), subscale scores tend to be heavily skewed in ICPs (Crombez et al., 2008). Therefore, we decided to slightly adjust the wording of 13 out of 14 items and formulated them in a more extreme way, i.e., (1) solving pain; e.g., "I would try really everything to get rid of my pain"; (2) meaningfulness of life despite pain; e.g., "Even when in pain, I still find my life meaningful"; (3) acceptance of the insolubility of pain; e.g., "I can live with the idea that there exists no solution for my pain"; (4) belief in a solution; e.g., "I am truly convinced that there is a treatment for my pain". Cronbach's alpha's in this study were $\alpha=0.85,0.86,0.78$, and 0.86 , respectively, for the four scales. Subsequent analyses showed that three (i.e., solving pain, acceptance of the insolubility of pain, and belief in a solution) out of the four subscales met criteria for normal distribution.

The Dutch version of the Pain Catastrophizing Scale (PCS-; Sullivan et al., 1995; Crombez et al., 1998) was used to measure catastrophic thinking about pain. It is a 13-item scale for both non-clinical and clinical populations. Participants are asked to reflect on past painful experiences and to indicate the degree to which they experienced each of the 13 thoughts or feelings during pain on a 5-point scale (e.g., "I can't seem to keep it out of my mind", or "I become afraid that the pain may get worse"). Scores range from 0 to 4 . The PCS has shown to be valid and highly reliable (Osman et al., 2000; Van Damme et al., 2002). Cronbach's alpha in this study was $\alpha=0.90$.

\section{Procedure}

A self-report assessment and a semi-structured interview were employed. First, participants were invited to fill in a set of questionnaires at home. These could be completed online (i.e., Limesurvey, $n=62)$ or on paper $(n=11)$. Next, participants were invited to the university. Participants were further informed about the study and provided a written consent. They were then requested to provide socio-demographic information and completed some brief questions about their pain. Subsequently, participants responded to the Personal Project Analysis through a semi-structured interview format.

\section{Statistical Strategy}

Data were analyzed using the Statistical Package for Social Sciences (SPSS 20.0) and Microsoft Excell 2007 for Windows (Microsoft ${ }^{\circledR}$ Office Excell ${ }^{\circledR}$ 2007). Counting the number of times a participant mentioned at least one goal of a specific category and calculating relative percentages, enabled us to investigate the frequency of goal types reported by our sample.

As we were only interested in the effects of the pain control goal (Goal C) on the other two goals (goal A en B), we averaged the ratings of the two non-pain goals for all further statistical analyses. Descriptive statistics (mean, $S D$ ) were calculated for each of the goal appraisals of both the pain as well as nonpain goals. Further, a series of pairwise $t$-tests or non-parametric Wilcoxon signed-rank tests was conducted to examine whether there was a significant difference in how ICPs appraised their pain control goal compared to their non-pain goals. To obtain a standardized measure of the magnitude of the observed effects, i.e., a standardized difference between two means, effect sizes (Cohen's $d$ ) for independent samples were calculated using Morris and DeShon's formula (Borenstein et al., 2009). The 95\% confidence interval $(95 \% \mathrm{CI})$ was also calculated. Cohen's $d$ is an effect size that is not design-dependent and conventional norms are available (Field, 2005). We determined whether Cohen's $d$ was small (0.20), medium (0.50), or large (0.80) (Cohen, 1988). Lastly, Pearson correlations or non-parametric Kendall's tau correlations were calculated to describe the association between goal appraisals on the one hand and problem solving, acceptance, and catastrophizing about pain on the other hand.

In order to examine whether participants reported high levels of pain goal interference, facilitation and necessity, we focused upon the effects of the pain control goal (Goal C) on the other two goals (goal A en B). We calculated descriptive statistics (mean, $S D$ ), frequencies and proportions of response options across the sample. We used response options $\geq 4$ as indicators of high levels (Riediger and Freund, 2004). Furthermore, Pearson or Kendall's tau correlations were calculated to assess associations between intergoal variables. Lastly, Pearson or Kendall's tau correlations were calculated to examine associations between pain control goal interference, facilitation and necessary condition on the one hand and solving pain, acceptance and catastrophizing on the other hand.

\section{RESULTS}

\section{Type of Goals}

Participants listed an average of 5.76 goals $(S D=2.01$; range $3-12$ ). We found that $41.1 \%$ of the participants spontaneously reported at least one pain control goal. Also, participants frequently reported one or more goals in the following life domains: interpersonal (80.82\%), work/education $(49.32 \%)$, leisure time (46.58\%), exercise (45.21\%), and health/physical well-being $(41.10 \%)$. The least mentioned were goals related to social validation for one's pain (6.85\%). Table 1 shows examples of goals reported within each domain.

\section{Goal Appraisals}

Tables 2 and 3 display descriptive statistics on goal appraisals. A series of pairwise $t$-tests or non-parametric Wilcoxon-signed rank tests was conducted to examine whether there were significant differences in goal appraisals between one's pain and non-pain goals. Results indicated that participants rated the pain control goal as more difficult to achieve, $t(72)=-2.80, p=0.007$, Cohen's $d=0.38,95 \% \mathrm{CI}[0.11,0.66]$, and more stressful while pursuing, $t(72)=-2.09, p=0.04$, Cohen's $d=0.27,95 \%$ CI $[0.01,0.52]$ than the non-pain goals. Participants also reported to spend more time in achieving the pain control goal than the non-pain goals, $\mathrm{Z}=-2.48, p=0.013$, Cohen's $d=0.29$, 
TABLE 1 | Examples of goals provided by participants.

\begin{tabular}{|c|c|}
\hline Life domains & Sample goals \\
\hline Pain Control & To have less pain To live without pain \\
\hline Interpersonal & To build up social contact To maintain contact with friends \\
\hline Intrapersonal & To get to know and live with my limitations To be less anxious in contact with other people \\
\hline Health/Physical Well-being & To lose weight To sleep better \\
\hline Work/Education & To be able to work again To volunteer in helping students pass their language courses \\
\hline Finances & To have no financial worries To save money to be able to buy a car \\
\hline Leisure Time & To travel To do cultural stuff (e.g., concerts, musicals, expositions) \\
\hline House holding & To clean the house To be able to do the cooking \\
\hline Psychological/Mental Well-being & To be able to enjoy pleasant things (e.g., watching kids play together) To feel useful again \\
\hline Exercise & To be able to keep on doing exercise (e.g., swimming, walking) To improve my walking condition \\
\hline Social Validation & To have others to know what pain is about To be believed by other people \\
\hline Other & To grow old To wish everybody a good future \\
\hline
\end{tabular}

95\% CI $[-0.01,0.58]$. Of note, the pain control goal was rated to be related less to one's identity, $t(72)=2.85, p=0.006$, Cohen's $d=-0.38,95 \%$ CI $[-0.65,-0.11]$ than the non-pain goals. No significant differences between the pain control goal and the non-pain goals were found for importance, $Z=-0.90$, $p=0.367$, control, $Z=-0.64, p=0.523$, satisfaction with progress, $Z=-1.84, p=0.07$, and value, $Z=-0.53, p=0.595$.

Pearson or Kendall's tau correlations were calculated to investigate the association between goal appraisals and measures of problem solving, acceptance and catastrophic thinking about pain (see Tables 2 and 3 ). Higher levels of attempts to solve pain (PaSol) were related to rating the pain control goal as more important $(r=0.26)$ and more valuable $(r=0.29)$, and to a higher investment of time in the pain control goal $(r=0.32)$. Acceptance, i.e., acceptance of the insolubility of pain (PaSol) and meaningfulness of life despite pain ( $\mathrm{PaSol})$, were found to be positively related to satisfaction with progress in achieving both the pain control goal ( $r=0.28$ and $r=0.38$, respectively) and non-pain goals ( $r=0.43$ and $r=0.41$, respectively). Also, acceptance was found to be associated with lower ratings of stress in pursuing non-pain goals $(r=-0.40)$. Finally, catastrophizing about pain (PCS) was related to more stress while pursuing the

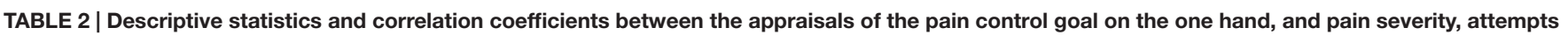
to control pain, meaningfulness of life despite pain, acceptance, and catastrophizing on the other hand.

\begin{tabular}{|c|c|c|c|c|c|c|c|}
\hline & $N$ & $M(\mathrm{SD})$ & Pain Severity (MPI) & Solving pain (PaSol) & Meaning-fulness ${ }^{b}$ (PaSol) & Acceptance (PaSol) & Catastrophizing (PCS \\
\hline Importance ${ }^{b}$ & 73 & $5.66(0.67)$ & 0.02 & $0.26 *$ & 0.12 & -0.09 & -0.07 \\
\hline Difficultya ${ }^{a}$ & 73 & $4.08(1.57)$ & $0.29 *$ & 0.09 & -0.12 & -0.20 & 0.19 \\
\hline Control $^{b}$ & 73 & $2.92(1.67)$ & -0.08 & -0.03 & $0.20^{*}$ & $0.24^{* *}$ & -0.16 \\
\hline Stress $^{a}$ & 73 & $3.37(1.70)$ & 0.07 & 0.11 & $-0.18^{* *}$ & -0.20 & $0.35^{* *}$ \\
\hline Time $^{b}$ & 73 & $4.32(1.51)$ & $0.25^{* *}$ & $0.32^{* * *}$ & 0.04 & -0.03 & 0.06 \\
\hline Progress $^{b}$ & 73 & $2.74(1.90)$ & $-0.18^{*}$ & -0.17 & $0.38^{* * *}$ & $0.28^{* *}$ & $-0.28^{* *}$ \\
\hline Self-Identity ${ }^{a}$ & 73 & $3.78(1.79)$ & -0.12 & 0.06 & 0.17 & 0.17 & -0.20 \\
\hline Value $^{\mathrm{b}}$ & 73 & $5.51(0.99)$ & 0.04 & $0.29 * *$ & 0.16 & 0.10 & -0.02 \\
\hline
\end{tabular}

apearson Correlations; 'bendall's tau correlations; PaSol, Pain Solutions Questionnaire; PCS, Pain Catastrophizing Scale. * $p<0.05 .{ }^{* *} p<0.01 .{ }^{* * *} p<0.001$.

TABLE 3 | Descriptive statistics and correlation coefficients between appraisals of the non-pain goals (averaged) on the one hand, and pain severity, attempts to solve pain, meaningfulness of life despite pain, acceptance, and catastrophizing on the other hand.

\begin{tabular}{|c|c|c|c|c|c|c|c|}
\hline & $N$ & $M(S D)$ & Pain Severity (MPI) & Solving pain (PaSol) & Meaningfulness $^{\mathrm{b}}$ (PaSol) & Acceptance (PaSol) & Catastrophizing (PCS) \\
\hline Importance ${ }^{b}$ & 73 & $5.61(0.47)$ & 0.05 & 0.08 & 0.08 & -0.01 & -0.06 \\
\hline Difficultya & 73 & $3.50(1.44)$ & 0.17 & $0.25^{*}$ & $-0.18^{*}$ & $-0.30^{*}$ & $0.37^{* *}$ \\
\hline Control $^{a}$ & 73 & $3.08(1.40)$ & -0.14 & -0.21 & $0.25^{* *}$ & $0.30 *$ & -0.15 \\
\hline Stress $^{a}$ & 73 & $2.92(1.68)$ & $0.30 * *$ & 0.19 & $-0.32^{* * *}$ & $-0.40^{* * *}$ & $0.43^{* * *}$ \\
\hline Time $^{a}$ & 73 & $3.95(1.01)$ & 0.10 & 0.13 & 0.16 & 0.12 & 0.05 \\
\hline Progress $^{a}$ & 73 & $3.21(1.50)$ & -0.17 & -0.16 & $0.41^{* * *}$ & $0.43^{* * *}$ & $-0.39^{* * *}$ \\
\hline Self-Identity ${ }^{a}$ & 73 & $4.37(1.17)$ & -0.11 & -0.18 & $0.21^{*}$ & $0.25^{*}$ & -0.21 \\
\hline Value $^{b}$ & 73 & $5.62(0.49)$ & 0.07 & 0.00 & 0.12 & -0.04 & -0.02 \\
\hline
\end{tabular}

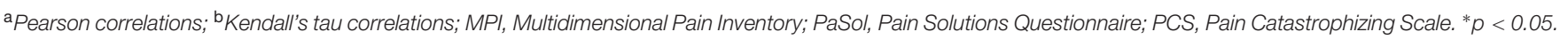
${ }^{* *} p<0.01$. ${ }^{* *} p<0.001$. 
pain control goal $(r=0.35)$ and the non-pain goals $(r=0.43)$, and to lower ratings of satisfaction with progress in achieving both the pain control goal $(r=-0.28)$ and the non-pain goals $(r=-0.39)$. Catastrophizing was also related to higher ratings of difficulty in achieving non-pain goals $(r=0.37)$.

\section{Intergoal Relationships}

Table 4 presents the descriptive statistics (mean, SD) of the intergoal variables. High levels (response options $\geq 4$ ) of pain control goal interference were reported by $50 \%$ of the participants, $80.15 \%$ reported high amounts of pain control goal facilitation, and $59.55 \%$ showed high need to control pain before pursuing other goals (necessary condition). Pain goal interference was found to be unrelated to pain goal facilitation $(r=0.09)$. No significant association was found between pain goal facilitation and necessary condition $(r=0.08)$.

Table 4 presents the results of the correlational analyses between intergoal variables on the one hand, and problem solving, acceptance, and catastrophizing. Attempting to solve pain (PaSol) was associated with higher levels of facilitation of pain control goals on non-pain goals $(r=0.26)$. Acceptance of the insolubility of pain (PaSol) and meaningfulness of life despite pain ( $\mathrm{PaSol})$, were related to lower levels of necessity of achieving the pain control goal upon pursuing one's non-pain goals ( $r=-0.31$ and $r=-0.20$, respectively). Catastrophizing about pain (PCS) was related to higher levels of necessity of achieving the pain control goal upon pursuing one's non-pain goals $(r=0.40)$.

\section{DISCUSSION}

This study investigated (1) which goals are spontaneously elicited by ICPs, (2) how ICPs appraise their pain control goals, and whether these differ from non-pain goal appraisals, (3) how the pursuit of pain control goals affects the working on non-pain goals, and (4) whether the goal appraisals and interrelations are related to some key constructs involved in misdirected problem solving, such as attempts to solve pain, acceptance and catastrophic thinking about pain.

Individuals with chronic pains pursued a wide array of personal goals, and although we did not perform an in-depth analysis of their content, they seem to be quite similar to the goals that other individuals report (PPA, Little, 1983). Surprisingly, pain control goals, i.e., goals related to the control and management of pain, were not overly salient in our sample. Only about $40 \%$ spontaneously provided a goal related to attempts to control pain. One may have expected a larger percentage. However, several reasons may account for this finding. First, we mainly focused upon the goal to control pain. When categorizing the content of the goals, it became apparent that other painrelated goals were also pursued. The content of about $7 \%$ of goals were related to social validation. It seems that next to attempting to try to control pain, being believed by others that the pain is real, is a concern for a subgroup of ICPs (Kool et al., 2013). More research on this largely neglected topic is warranted (Hamilton et al., 2005; De Ruddere and Craig, 2016). Second, the study took place in a research context and not in a clinical setting, in which pain control may be more salient. Relatedly, participants were recruited from a patient association group, and not from a specialist clinic or rehabilitation center. It is likely that not all these individuals show tenacity in trying to solve their pain (Crombez et al., 2008). Third, in the instructions regarding the goal elicitation procedure, ICPs were not prompted with the example of a pain control goal.

Overall, the pattern of results indicates that attempting to control pain is a time-consuming and frustrating enterprise in ICPs (McCracken and Eccleston, 2003, 2005; Eccleston and Crombez, 2007). Participants indicated that their pain control goal was more difficult to achieve, more stressful, and required more of their time than their non-pain goals. They also experienced their pain control goal as less representative for their identity than the non-pain goals. Also, the pattern of correlations is in line with this picture. ICPs who report to be more engaged in solving pain, rated the goal to control pain as more important and valuable, and invested more time in it. Not accepting that pain is insoluble and not believing that life is meaningful despite pain were both associated with being less satisfied with the progress on pain control goals.

A noteworthy finding is that individual differences in attempts to solve pain were not only related to appraisals of the pain control goal, but also to appraisals of the non-pain goals. ICPs who reported to be more engaged in solving pain also reported more difficulties in achieving their non-pain goals. This was

TABLE 4 | Results of correlational analyses between pain goal interference, facilitation and necessary condition, and solving pain, meaningfulness of life despite pain, acceptance, and catastrophizing.

\begin{tabular}{|c|c|c|c|c|c|c|c|c|}
\hline & $M(S D)$ & 2 & 3 & 4 & 5 & 6 & 7 & 8 \\
\hline 1. Pain Goal Interference ${ }^{a}$ & $3.16(1.04)$ & 0.08 & 0.16 & 0.10 & $0.23^{+}$ & -0.08 & -0.21 & 0.09 \\
\hline 2. Pain Goal Facilitation ${ }^{b}$ & $4.00(0.84)$ & & 0.08 & 0.05 & $0.26^{* *}$ & 0.04 & -0.02 & 0.05 \\
\hline 3. Necessary Condition ${ }^{a}$ & $3.58(1.04)$ & & & 0.16 & 0.07 & $-0.20^{*}$ & $-0.31^{* *}$ & $0.40^{* * *}$ \\
\hline 4. Pain intensity (MPI) & $11.78(2.73)$ & & & & $0.38^{* *}$ & $-0.32^{* *}$ & $-0.28^{*}$ & $0.35^{* *}$ \\
\hline 5. Solving pain $(\mathrm{PaSol})^{\mathrm{a}}$ & $16.53(5.62)$ & & & & & -0.08 & -0.31 & $0.34^{* *}$ \\
\hline 6. Meaningfulness $(\mathrm{PaSol})^{\mathrm{b}}$ & $20.88(5.60)$ & & & & & & $0.55^{* *}$ & $-0.35^{* *}$ \\
\hline 7. Acceptance (PaSol) ${ }^{a}$ & $8.78(4.56)$ & & & & & & & $-0.39^{* *}$ \\
\hline 8. Catastrophizing (PCS) ${ }^{a}$ & $23.25(10.06)$ & & & & & & & \\
\hline
\end{tabular}

a Pearson correlations; ' ${ }^{\prime}$ Kendall's tau correlations; PaSol, Pain Solutions Questionnaire; PCS, Pain Catastrophizing Scale. ${ }^{+} p=0.05 .{ }^{*} p<0.05 .{ }^{* *} p<0.01 .{ }^{* * *} p<0.001$. 
also the case for ICPs who do not accept that their pain is insoluble and do not believe that life is meaningful despite pain. The latter two variables were also related to experiencing more stress and less progress during the pursuit of the non-pain goals. There are several avenues to make sense of these data. First, it may be that attempts to solve pain come along with costs in pursuing other goals (Riediger and Freund, 2004). If this is the case one would expect that ICPs also report that working on the pain control goal interferes with the pursuit of nonpain goals. Further data of our study seem to corroborate this interpretation. ICPs who cannot accept pain as insoluble and do not believe that life is meaningful despite pain, report that solving pain is necessary in order to pursue their non-pain goals. Likewise, ICPs who engage more in attempts to solve pain also report more interference of their pain control goal with non-pain goals, although this effect failed to reach statistical significance. Second, it may be that attempts to solve pain are fueled by the interfering effect of pain on goal-related activities. Indeed, in many self-regulation models (Karoly, 1993; Carver and Scheier, 1998; Brandtstädter and Rothermund, 2002) coping and problem solving are triggered by goal interference, an experience that is highly prevalent in ICPs (Karoly and Ruehlman, 2007).

An important objective of this study was to investigate the goal structure or how ICPs experience the relationships between pain and non-pain goals. More specifically, we explored whether working on pain control goals facilitated working on non-pain goals (pain goal facilitation), whether working on pain control goals interfered with working on non-pain goals, and whether achievement of pain control goals is deemed necessary to attain non-pain goals (necessary condition). Despite the extensive piloting with the precise format of the items, some methodological issues remain. First, necessary condition is logically a part of the larger construct of pain goal facilitation. We would then expect a positive association between both, which, however, was not the case. Second, participants reported that the questions on goal interrelations were difficult. It is our impression that overall, the necessity item made more sense than the items on facilitation and interference. Notwithstanding, the pattern of results on the goal structure is intriguing, especially related to the necessity to solve pain in order to pursue non-pain goals. Most notable was our finding that perceiving one's pain control goal as necessary for achieving other goals, was related to accepting less that pain is insoluble and believing less that life is meaningful despite pain. These findings resonate with the idea of Conditional Goal Setting (CGS; Street, 2002; Street et al., 2007). CGS refers to the mechanism of goal linking, which means that a lower order goal (e.g., to control my pain) is conditionally linked to a higher order value (e.g., be happy). Through goal linking, the lower order goal gains significant importance, and will become difficult to disengage from. As a result, depression and distress may increase (Street, 2002; Street et al., 2007). As such, CGS theory may help explaining tenacious efforts to achieve pain control and resulting distress. Solving pain may become a necessary mean to continue with their life. Individuals may then become stuck in their attempts to solve pain, as an easy solution is not at hand.

Our results challenge some current understandings of catastrophizing about pain, and call for a conceptual broadening.
Catastrophizing has been found a robust predictor of pain-related distress and disability in cross-sectional and longitudinal studies (Peters et al., 2007). Traditionally, catastrophizing is defined as an exaggerated negative mental set brought to bear during actual or anticipated pain experience (Sullivan et al., 2001). This is also evidenced in the influential fear-avoidance model. According to this model, those who catastrophize about pain develop erroneous fears about their pain [fear of (re)injury], which lead to avoidance of pain-evoking activities (Vlaeyen and Linton, 2000). Our results indicate that more might be at stake. Individuals who catastrophized about pain reported also elevated levels of stress in pursuing non-pain goals and less satisfaction with progress toward these goals. Those individuals also perceived their pain control goal as a necessary condition for pursuing their nonpain goals. Catastrophizing may thus not be limited to the mere experience of pain, but may extend to the experienced interference of daily goals by pain, possibly resulting in worrying and attempts to problem solving (Eccleston and Crombez, 2007; Crombez et al., 2012).

There are some limitations to this study. First, we adopted a goal and self-regulation perspective (Karoly, 1993; Little, 1998; Crombez et al., 2012) to frame our research and interpret our findings. However, our data are also compatible with other theoretical perspectives, amongst which the psychological flexibility (PF) model (Kashdan and Rottenberg, 2010; McCracken and Morley, 2014). PF could be described as the capacity to be fully in contact with the present moment without needless defense against pain, and to persist or change behavior in function of one's goals despite pain. For example, our findings on the potential negative effect of seeing pain control as necessary to allow pursuit of other non-pain goals, could be easily translated to PF language. (Hayes et al., 2012; Trompetter et al., 2015; Yu and McCracken, 2016). Second, results of this study are based on cross-sectional data, so we cannot infer causality. The use of moment-to-moment assessment by, for instance, diary approaches and the use of longitudinal designs will be necessary to allow causal inferences. A third limitation relates to sample characteristics. Within this study, we have explored goals in a self-defined chronic pain population, which may not be a representative sample of patients. Fourth, only a limited number of standard goal appraisals were assessed. Other dimensions are possible and may be of further relevance to help understand how patients juggle between the pain and non-pain goals. Fifth, we limited our focus to the goal of controlling pain. However, other pain-related goals, such as being believed by others that the pain is real, may also be at stake and important to assess (Karoly and Jensen, 1987; Hamilton et al., 2005).

\section{AUTHOR CONTRIBUTIONS}

GC has initiated and developed research ideas and design, and finalized paper. EL was involved in developing research ideas and design, collected and analysed the data, and made a first draft of the paper. LG was involved in developing the research design, and providing feedback on the paper. SD was involved in 
developing the research design and ideas, and provided feedback on the paper.

\section{ACKNOWLEDGMENTS}

The authors thank Celine Bastien and Charlotte Aertsen for their assistance in recruitment, data collection and coding,

\section{REFERENCES}

Affleck, G., Tennen, H., Urrows, S., Higgins, P., Abeles, M., Hall, C., et al. (1998). Fibromyalgia and women's pursuit of personal goals: a daily process analysis. Health Psychol. 17, 40-47. doi: 10.1037//0278-6133.17.1.4

Affleck, G., Tennen, H., Zautra, A., Urrows, S., Abeles, M., and Karoly, P. (2001). Women's pursuit of personal goals in daily life with fibromyalgia: a valueexpectancy analysis. J. Consult. Clin. Psychol. 69, 587-596. doi: 10.1037/0022006X.69.4.587

Aldrich, S., Eccleston, C., and Crombez, G. (2000). Worrying about chronic pain: vigilance to threat and misdirected problem solving. Behav. Res. Ther. 38, 457-470. doi: 10.1016/S0005-7967(99)00062-5

Austin, J. T., and Vancouver, J. B. (1996). Goal constructs in psychology: structure, process, and content. Psychol. Bull. 120, 338-375. doi: 10.1037//00332909.120.3.338

Borenstein, M., Hedges, L. V., Higgins, J. P. T., and Rothstein, H. R. (2009). Introduction to Meta-Analysis. West Sussex: Wiley.

Brandtstädter, J., and Rothermund, K. (2002). The life-course dynamics of goal pursuit and goal adjustment: a two-process framework. Dev. Rev. 22, 117-150. doi: 10.1006/drev.2001.0539

Carver, C. S., and Scheier, M. F. (1998). On the Self-Regulation of Behavior. New York, NY: Cambridge University Press.

Chulef, A. S., Read, S. J., and Walsh, D. A. (2001). A hierarchical taxonomy of human goals. Motiv. Emot. 25, 191-123. doi: 10.1023/A:10122252 23418

Cohen, J. (1988). Statistical Power Analysis for the Behavioral Sciences. San Diego, CA: McGraw-Hill.

Crombez, G., Eccleston, C., Baeyens, F., and Eelen, P. (1998). When somatic information threatens, catastrophic thinking enhances attentional interference. Pain 75, 187-198. doi: 10.1016/S0304-3959(97)00219-4

Crombez, G., Eccleston, C., Van Damme, S., Vlaeyen, J. W. S., and Karoly, P. (2012). Fear-avoidance model of chronic pain: the next generation. Clin. J. Pain 28, 475-483. doi: 10.1097/AJP.0b013e3182385392

Crombez, G., Eccleston, C., Van Hamme, G., and De Vlieger, P. (2008). Attempting to solve the problem of pain: a questionnaire study in acute and chronic pain patients. Pain 3, 556-563. doi: 10.1016/j.pain.2007.10.020

De Ruddere, L., and Craig, K. D. (2016). Understanding stigma and chronic pain: a state of the art review. Pain doi: 10.1097/j.pain.0000000000000512 [Epub ahead of print].

De Vlieger, P., Van den Bussche, E., Eccleston, C., and Crombez, G. (2006). Finding a solution to the problem of pain: conceptual formulation and the development of the pain solutions questionnaire (PaSoL). Pain 123, 285-293. doi: $10.1016 /$ j.pain.2006.03.005

Eccleston, C., and Crombez, G. (2007). Worry and chronic pain: a misdirected problem solving model. Pain 132, 233-236. doi: 10.1016/j.pain.2007.09.014

Field, A. (2005). Discovering Statistics using SPSS, 2nd Edn. London: Sage Publications.

Hamilton, N. A., Karoly, P., and Zautra, A. J. (2005). Health goal cognition and adjustment in women with fibromyalgia. J. Behav. Med. 28, 455-466. doi: 10.1007/s10865-005-9013-8

Hardy, J. K., Crofford, L. J., and Segerstrom, S. C. (2011). Goal conflict, distress, and pain in women with fibromyalgia: a daily diary study. J. Psychosom. Res. 70, 534-540. doi: 10.1016/j.jpsychores.2010.10.013

Hayes, S. C., Pistorello, J., and Levin, M. E. (2012). Acceptance and commitment therapy as a unified model of behavior change. Couns. Psychol. 40, 976-1002 . doi: $10.1177 / 0011000012460836$

Karoly, P. (1993). Mechanisms of self-regulation: a systems view. Annu. Rev. Psychol. 44, 23-52. doi: 10.1146/annurev.psych.44.1.23
Lore Van Hulle and Dimitri Van Ryckeghem for helping to recruit participants, the Flemish Pain League for collection of data, Michaela Riediger for providing us the original Intergoal Relation Questionnaire and coding material, and Annabelle Casier, Marieke Dewitte, Marielle Goossens, Madelon Peters, and Johan Vlaeyen for their assistance in translating the Intergoal Relations Questionnaire.

Karoly, P., and Lecci, L. (1997). Motivational correlates of self-reported persistent pain in young adults. Clin. J. Pain 13, 104-109. doi: 10.1097/00002508199706000-00004

Karoly, P., Okun, M. A., Ruehlman, L. S., and Pugliese, J. A. (2008). The impact of goal cognition and pain severity on disability and depression in adults with chronic pain: an examination of direct effects and mediated effects via paininduced fear. Cogn. Ther. Res. 32, 418-433. doi: 10.1007/s10608-007-9136-Z

Karoly, P., and Ruehlman, L. S. (1996). Motivational implications of pain: chronicity, psychological distress, and work goal construal in a national sample of adults. Health Psychol. 15, 383-390. doi: 10.1037//0278-6133.15.5.383

Karoly, P., and Ruehlman, L. S. (2007). Psychosocial aspects of pain-related life task interference: an exploratory analysis in a general population sample. Pain Med. 8, 563-572. doi: 10.1111/j.1526-4637.2006.00230.x

Karoly, P. J., and Jensen, M. P. (1987). Multimethod Assessment of Chronic Pain. New York, NY: Pergamon Press.

Kashdan, T. B., and Rottenberg, J. (2010). Psychological flexibility as a fundamental aspect of health. Clin. Psychol. Rev. 30, 865-878. doi: 10.1016/j.cpr.2010.03.001

Kool, M. B., van Middendorp, H., Lumley, M. A., Bijlsma, J. W. J., and Geenen, R. (2013). Social support and invalidation by others contribute uniquely to the understanding of physical and mental health of patients with rheumatic diseases. J. Health Psychol. 18, 86-95. doi: 10.1177/1359105312436438

Little, B. R. (1983). Personal projects: A rationale and method for investigation. Environ. Behav. 15, 273-309. doi: 10.1177/0013916583153002

Little, B. R. (1989). "Personal projects analysis: trivial pursuits, magnificent obsessions, and the search for coherence," in Personality Psychology: Recent Trends and Emerging Directions, eds D. M. Buss and N. Cantor (New York, NY: Springer-Verlag), 15-31.

Little, B. R. (1998). "Personal project pursuit: dimensions and dynamics of personal meaning," in The Human Quest for Meaning: A Handbook of Psychological Research and Clinical Applications, eds P. T. P. Wong and P. S. Fry, (Mahwah, NJ: Lawrence Erlbaum Associates), 193-212.

Little, B. R., and Chambers, M. C. (2004). "Personal project pursuit: on human doings and well-beings," in Handbook of Motivational Counseling. Concept, Approaches, and Assessment, eds W. M. Cox and E. Klinger (West-Sussex: John Wiley \& Sons), 65-82.

Little, B. R., and Gee, T. L. (2007). "The methodology of personal project analysis: four modules and a funnel," in Personal Project Pursuit: Goals, Action, and Human Flourishing, eds B. R. Little, K. Salmelo-Aro, and S. D. Phillips (London: Lawrence Erlbaum Associates), 51-92.

Lousberg, R., Van Breukelen, G. J. P., Groenman, N. H., Schmidt, A. J. M., Arntz, A., and Winter, F. A. M. (1999). Psychometric properties of the Multidimensional Pain Inventory, Dutch language version (MPI-DLV). Behav. Res. Ther. 37, 167-182. doi: 10.1016/S0005-7967(98)00137-5

Malec, J., Glasgow, R. E., Ely, R., and Kling. (1977). Coping with pain: a selfmanagement approach. JSAS Catal. Sel. Doc. Psychol. 7, 113.

McCracken, L. M., and Eccleston, C. (2003). Coping or acceptance: what to do about chronic pain? Pain 105, 197-204. doi: 10.1016/S0304-3959(03)00202-1

McCracken, L. M., and Eccleston, C. (2005). A prospective study of acceptance of pain and patient functioning with chronic pain. Pain 118, 164-169. doi: 10.1016/j.pain.2005.08.015

McCracken, L. M., and Morley, S. (2014). The psychological flexibility model: a basis for integration and progress in psychological approaches to chronic pain management. J. Pain 15, 221-234. doi: 10.1016/j.jpain.2013.10.014

Ogilvie, D. M., Rose, K. M., and Heppen, J. B. (2001). A comparison of personal project motives in three age groups. Basic Appl. Soc. Psychol. 23, 207-215. doi: $10.1207 / 153248301750433768$

Osman, A., Barrios, F. X., Gutierrez, P. M., Koppen, B. A., Merrifield, T., and Gritmann, L. (2000). The pain catastrophizing scale: further psychometric 
evaluation with adult samples. J. Behav. Med. 23, 351-365. doi: 10.1023/ A: 1005548801037

Peters, M. L., Sommer, M., de Rijke, J. M., Kessels, F., Heineman, E., Patijn, J., et al. (2007). Somatic and psychologic predictors of long-term unfavorable outcome after surgical intervention. Ann. Surg. 245, 487-494. doi: 10.1097/01.sla. 0000245495.79781 .65

Riediger, M., and Freund, A. M. (2004). Interference and facilitation among personal goals: differential associations with subjective well-being and persistent goal pursuit. Pers. Soc. Psychol. Bull. 30, 1511-1523. doi: 10.1177/ 0146167204271184

Rozin, P. (2009). What kind of empirical research should we publish, fund and reward? A different perspective. Perspect. Psychol. Sci. 4, 435-439. doi: 10.1111/j.1745-6924.2009.01151

Street, H. (2002). Exploring relationships between goal setting, goal pursuit and depression: a review. Aust. Psychol. 37, 95-103. doi: 10.1080/ 00050060210001706736

Street, H., O'Connor, M., and Robinson, H. (2007). Depression in older adults: exploring the relationship between goal setting and physical health. Int. J. Geriatr. Psychol. 22, 1115-1119. doi: 10.1002/gps.1797

Sullivan, M. J., Thorn, B., Haythornthwaite, J. A., Keefe, F., Martin, M., Bradley, L. A., et al. (2001). Theoretical perspectives on the relation between catastrophizing and pain. Clin. J. Pain 17, 52-64. doi: 10.1097/00002508200103000-00008

Sullivan, M. J. L., Bishop, S. R., and Pivik, M. A. (1995). The pain catastrophizing scale: development and validation. Psychol. Assess. 7, 524-532. doi: 10.1037//1040-3590.7.4.524

Trompetter, H. R., Bohlmeijer, E. T., Fox, J. P., and Schreurs, K. M. G. (2015). Psychological flexibility and catastrophizing as associated change mechanisms during online Acceptance \& Commitment Therapy for chronic pain. Behav. Res. Ther. 74, 50-59. doi: 10.1016/j.brat.2015.09.001

Van Damme, S., Crombez, G., Bijttebier, P., Goubert, L., and Van Houdenhove, B. (2002). Confirmatory factor analysis of the pain catastrophizing scale: invariant factor structure across clinical and non-clinical populations. Pain 96, 319-324. doi: 10.1016/S0304-3959(01)00463-8

Van Damme, S., Crombez, G., and Eccleston, C. (2008). Coping with pain: a motivational perspective. Pain 139, 1-4. doi: 10.1016/j.pain.2008. 07.022

Viane, I., Crombez, G., Eccleston, C., Poppe, C., Devulder, J., Van Houdenhove, B., et al. (2003). Acceptance of pain is an independent predictor of mental wellbeing in patients with chronic pain: empirical evidence and reappraisal. Pain 106, 65-72. doi: 10.1016/S0304-3959(03)00291-4

Vlaeyen, J. W. S., and Linton, S. J. (2000). Fear-avoidance and its consequences in chronic musculoskeletal pain: a state of the art. Pain 85, 317-332. doi: 10.1016/S0304-3959(99)00242-0

Yu, L., and McCracken, L. M. (2016). Model and processes of acceptance and commitment therapy (ACT) for chronic pain including a closer look at the self. Curr. Pain Headache Rep. 20, 12. doi: 10.1007/s11916-0160541-4

Conflict of Interest Statement: The authors declare that the research was conducted in the absence of any commercial or financial relationships that could be construed as a potential conflict of interest.

The reviewer HT and handling Editor declared their shared affiliation, and the handling Editor states that the process nevertheless met the standards of a fair and objective review.

Copyright (c) 2016 Crombez, Lauwerier, Goubert and Van Damme. This is an openaccess article distributed under the terms of the Creative Commons Attribution License (CC BY). The use, distribution or reproduction in other forums is permitted, provided the original author(s) or licensor are credited and that the original publication in this journal is cited, in accordance with accepted academic practice. No use, distribution or reproduction is permitted which does not comply with these terms. 